\title{
Face masks for the public during Covid-19: an appeal for caution in policy
}

\author{
Graham P. Martin*, University of Cambridge \\ Esmée Hanna, De Montfort University \\ Robert Dingwall, Dingwall Enterprises Ltd / Nottingham Trent University
}

Greenhalgh and colleagues argue in their recent $B M J$ analysis piece that policymakers should encourage the public to wear face masks, as the Covid-19 crisis continues to deepen. ${ }^{1}$ The evidence for such a measure, they acknowledge, remains sparse. Two systematic reviews—both currently unreviewed preprints—conclude that "the evidence is not sufficiently strong to support widespread use of facemasks as a protective measure against COVID19,"² and that "masks alone have no significant effect in interrupting spread of [influenza-like illnesses ...] or influenza."3 Another preprint review, with more opaque methods but encompassing an eclectic range of disciplinary perspectives, is more positive, recommending "adoption of public cloth mask wearing, as an effective form of source control, in conjunction with existing hygiene, distancing, and contact tracing strategies."4 With the lead author of this review, Greenhalgh has written a public-facing summary of the evidence, concluding that "assessment of this evidence leads us to a clear conclusion: keep your droplets to yourself wear a mask."5

In the absence of a clear consensus on the value or otherwise of wearing face masks in community settings, Greenhalgh et al. invoke the precautionary principle. While the uncertainties may be real, they suggest, enough evidence exists to suggest plausible, if not probable, benefit—and equally importantly, that the downsides are either negligible or improbable. ${ }^{1}$ With roots in the social scientific literature on science and innovation policy, the precautionary principle is usually used to advise caution in the uptake of innovations with known benefits but uncertain or unmeasurable downsides, for example through restrictive regulation..$^{6,7}$ Examples include the 1992 Rio Declaration on Environment and Development, the 2002 Cartagena Protocol on Biosafety, and a wide range of national efforts to control individuals' exposure to radiation. ${ }^{8}$ Greenhalgh et al. approach the question from the opposite angle: that the risks of not acting are great, that the risks of acting are minimal and the potential benefits strong, and so action is imperative. They offer four sets of possible counter-

\footnotetext{
* Correspondence to: Graham Martin, The Healthcare Improvement Studies Institute, Department of Public Health and Primary Care, University of Cambridge. E-mail graham.martin@thisinstitute.cam.ac.uk.
} 
arguments: the lack of evidence of effectiveness; the risk of poor adherence and thus reduced effectiveness; the potential for 'risk compensation'9 (whereby mask-wearers, feeling safer, fail to observe other measures, such as hand hygiene or social distancing); and the potential impact on mask supplies, particularly for healthcare workers. Given the unprecedented circumstances of the outbreak, they suggest that these arguments are either invalid, or outweighed by the likely upsides.

We agree with Greenhalgh and colleagues that rapid translation of scientific knowledge into policy and practice is vital in a time of crisis. We also acknowledge that the likelihood of a definitive scientific evidence base on this topic is vanishingly small, given not only the timeframes, but also the methodological challenges posed by the subject, and its inherently multidisciplinary nature. However, we believe that the potential downsides of a policy shift towards the mass adoption of face masks deserve a greater airing. Correspondingly, we urge restraint in communication to both policymakers and the public on the subject-and suggest that the current crisis makes caution in science communication more important, not less.

\section{Mass uptake of face masks in community settings: the possible downsides}

Crudely, the case against a shift in policy might be made at five levels: the weaknesses in the evidence base for adoption of face masks in community settings; potential unintended consequences at individual level; potential unintended consequences at the microsocial level; potential unintended consequences at the macrosocial level; and the unknown and difficult-to-anticipate consequences of introducing a complex intervention. We briefly discuss each in turn.

First, the very weak evidence for face masks should be reiterated. Although some important studies followed the outbreak of SARS-Cov-1 in the 2000s, by and large the quality and clarity of the evidence base for face masks as a means of reducing transmission is disappointing. Few studies examine use of face masks in community settings; those that do find no evidence of reduced transmission compared with no face masks. ${ }^{3}$ Observational studies of face mask usage are, as one might expect, heavily confounded by the parallel implementation of other measures such as social distancing and isolation; experimental studies are limited by the impossibility of blinding and thus weak adherence in intervention and control groups. ${ }^{2}$ Of course, absence of evidence is not evidence of absence, and both recent systematic reviews cautiously suggest that in some circumstances, wearing of face masks may be warranted (in "community settings where contact may be casual and 
relatively brief,"2 and in clinical settings ${ }^{3}$ ). But existing research also provides little information on potential harms, such as "discomfort, dehydration, facial dermatitis, distress, headaches, exhaustion." ${ }^{3}$ Here, too, absence of evidence should not be taken as evidence of absence.

Second, it is unclear how well equipped the general public is to make proper use of face masks, or how readily good practice might be disseminated and taken up. Appropriate use of face masks is challenging and is something healthcare workers themselves can struggle with; ${ }^{10}$ poor use (including poor fitting, adjustment, touching) can reduce effectiveness and pose an infection risk in itself. Used disposable face masks must be removed and discarded properly because they accumulate pathogens; ${ }^{11}$ inappropriately discarded masks present an infection risk. For non-disposable clothbased masks, the evidence base is slim, though one hospital-based three-arm trial found worse infection outcomes in wearers of cloth masks than in wearers of medical masks and in a control group (usual practice, which included much mask-wearing)..$^{12}$ Cloth masks will retain moisture, with indeterminate consequences for their efficacy and for the creation of a microbiological environment favourable to other bacterial or viral organisms. Greenhalgh and Howard advocate homemade masks fashioned from a "t-shirt, handkerchief, or paper towel, or [...] a scarf or bandana around your face," ideally using "tightly woven fabric" and "including a layer of paper towel as a disposable filter." 5 The availability of time, space and materials to prepare, don and properly disinfect a homemade face mask is likely to vary markedly by socio-economic and other demographic characteristics. An evidence base for homemade masks is likely to be elusive. However, the existing research, coupled with the potential for great variation in materials, fit, adherence, touching and adjustment, doffing, disposal, frequency of laundering and so on, suggests the need for caution in advising widespread uptake, especially given the paucity of evidence for cloth face masks, their use, and their possible microbiological downsides.

Third, at the microsocial level, the argument might be made that encouraging uptake of face masks might lead to reduced compliance with other measures, due to the false sense of security presented by the mask. Such arguments rest on evidence around risk compensation in other areas of public health, for example seatbelts, ${ }^{13}$ cycle helmets, ${ }^{14}$ vaccination against sexually transmitted infections, ${ }^{15}$ and injury prevention in competitive sports. ${ }^{16}$ The evidence base in these fields is inconsistent, with some studies finding evidence of risk compensation (including risks to self and risks to others), and others finding no effect. ${ }^{9}$ Moreover, its transferability to the case of face masks is not self-evident, 
given the unprecedented nature of the Covid-19 crisis, and the fact that these interventions are primarily oriented towards the safety of the individual, whereas the case made by Greenhalgh and colleagues is premised on protecting public health. Nevertheless, there is a case that face masks might promote, if not active risk-taking, then at least a complacency that might reduce adherence to other measures, especially given the largely collective rather than individual benefits that the wearing of masks seeks to address. Such complacency might be mitigated by the more selective use of face masks in certain higher-risk environments suggested by Brainard et al., ${ }^{2}$ which might do more to maintain their additive role and the importance of proper use. There is also an argument that universal mask-wearing might aggravate the climate of fear already documented for Covid-19, ${ }^{17}$ adding to mental health concerns by providing a constant reminder of the threat posed by other humans.

Fourth, potential downsides of the promotion of face masks in community settings present themselves at the macrosocial level. Greenhalgh et al. acknowledge that wider uptake of masks might result in greater pressure on supply chains for healthcare workers, but argue that the proper response is to produce more masks. ${ }^{1}$ Given the likely sustained demand for masks, however, and in light of the difficulty of procuring appropriate personal protective equipment for healthcare workers in the UK and elsewhere,$^{18}$ the ease with which such a call can be answered is questionable. Homemade cloth masks, Greenhalgh et al. suggest, might offer an interim solution, but if they prove ineffective or even turn out to be associated with negative outcomes, a rush to obtain equipment intended for use by healthcare workers is conceivable. The likely consequences for healthcare staff in such a scenario are stark. It has the potential to exacerbate health inequalities too-both within countries and internationally, with disparities in nations' ability to access supplies crucial in the response to Coronavirus already apparent, along achingly familiar lines. ${ }^{19}$ The sociological dynamics of widespread mask adoption are also difficult to anticipate but potentially adverse, particularly if encouragement to wear masks evolved into more coercive measures (as suggested by Greenhalgh and Howard5). As a highly visible symbol of virtuous behaviour, those who fail to comply-for example, because of respiratory ailments that make prolonged mask-wearing dangerous, ${ }^{20}$ or because of religious preferences such as beards worn by Sikh men or hijabs worn by Muslim women that may make mask-wearing difficult—may be subject to stigmatisation or worse. Even a permissive policy risks 'gold-plating', where over-compliance in particular settings effectively imposes a universal rule. ${ }^{21}$ Meanwhile, notwithstanding the weak evidence base for face masks as a standalone measure, 
businesses or states might see widespread or mandatory mask-wearing as a warrant for a premature return to 'business as usual', justifying unsafe workplaces or crowded commuting conditions in terms of the protection offered by masks.

This leads us to our final point. The consequences of a public health intervention of this natureparticularly, though not only, if legally mandated-are by their nature difficult to anticipate. Face masks (and measures to secure their uptake) are a complex intervention in a complex system: the results of a change of this nature are emergent, unpredictable, and potentially counterintuitive..$^{22,23}$ The nature of complex systems is such that the outcomes of intervention are never fully amenable to either prediction or evaluation, but it is nevertheless crucial to give due consideration to the harms that might accrue ${ }^{24}$-and to monitor the system's response and adapt accordingly. ${ }^{25}$ Given the bluntness of national and international policy as a mode of action, such adaptation may prove very challenging once a decision is made.

\section{Evidence and policy in unusual times}

To adopt an increasingly hackneyed turn of phrase, the challenges facing the world during the Covid19 epidemic are unprecedented. The need for action is urgent, and so both demand for, and supply of, evidence-informed policy recommendations has increased sharply. Researchers and policymakers face a common challenge: what to do in the face of competing forms of expertise, inconclusive evidence, and timelines that preclude the development of a more adequate evidence base?

A definitive verdict on the circumstances in which face masks are most suitable is unlikely not only for these reasons, but also because evidence will necessarily be premised on value judgements, implicit or explicit. Rather than awaiting a consensus that will never arrive, it is incumbent upon researchers to engage with policymakers and the wider public to communicate science, inform public debate and increase the salience of evidence to policy decisions. However, in such engagement work it is also essential to be clear about the doubts, nuances and debates that remain. In their lay summary of the evidence around use of face masks in community settings, Greenhalgh and Howard declare that "the science says yes." 5 Their principal sources are Greenhalgh et al.'s analysis piece and Howard et al.'s literature review. ${ }^{1,4}$ At the time of writing, the Howard paper has not been subject to peer review. It is not a systematic review, and its two-sentence description of methods states that "a community-driven approach was used for building the paper list used." 4 The potential for bias in such an approach is 
self-evident. Meanwhile—again at the time of writing —-the WHO's guidance remains that use of face masks in community settings is not warranted, ${ }^{11}$ though of course this position is subject to review and change, as science advances and self-corrects.

Professor Greenhalgh's work during the Covid-19 crisis exemplifies engaged academia, marshalling diverse resources to co-produce high-quality evidence in response to pressing questions from policymakers and practitioners. Such engaged academic work, though, brings challenges. ${ }^{26}$ On this occasion, we believe public-facing communications regarding the scientific view on the balance of risks and benefits of widespread uptake of face masks have exceeded the scientific evidence base. Efforts to communicate a position so strongly in favour of widespread use of masks in the community, against current WHO advice and in the face of persistent evidence gaps and debates, risk promoting policy that is based more on eminence- - the track record, credentials and status of the authors-than on evidence. High-quality science communication involves communicating uncertainty as well as recommendation. ${ }^{27}$ The unintended consequences of unequivocal advocacy of a contested position go beyond the downsides of policy implementation: they include the potential erosion of trust in science as a field in general, when the measures put forward by science fail to live up to their promise, or result in problems that could be or had been anticipated.

We endorse Greenhalgh et al.'s call for more research on the use of face masks, and agree that useful knowledge is much more likely to arise from ecological studies, 'natural experiments' and other uncontrolled and non-experimental study designs. However, in the meantime, we urge adherence to the precautionary principle in science communication, given the risks that well-meaning action entails.

\section{Acknowledgement}

We thank Jane O'Hara for comments on an earlier draft of this manuscript. Responsibility for errors or omissions is the authors' alone.

\section{References}

1. Greenhalgh T, Schmid MB, Czypionka T, Bassler D, Gruer L. Face masks for the public during the covid-19 crisis. BMJ 2020 Apr 9;369. Available from:

http://www.bmj.com/content/369/bmj.m1435

2. Brainard JS, Jones N, Lake I, Hooper L, Hunter P. Facemasks and similar barriers to prevent respiratory illness such as COVID-19: a rapid systematic review. medRxiv. 2020 Apr $6 ; 2020.04 .01 .20049528$.

3. Jefferson T, Jones M, Ansari LAA, Bawazeer G, Beller E, Clark J, et al. Physical interventions to 
interrupt or reduce the spread of respiratory viruses. Part 1 - Face masks, eye protection and person distancing: systematic review and meta-analysis. medRxiv. $2020 \mathrm{Apr}$ 7;2020.03.30.20047217.

4. Howard J, Huang A, Li Z, Tufekci Z, Zdimal V, Westhuizen H-M van der, et al. Face masks against COVID-19: an evidence review. 2020 Apr 12; Available from:

https://www.preprints.org/manuscript/202004.0203/v1

5. Greenhalgh T, Howard J. Masks for all? The science says yes. Available from: https://www.fast.ai/2020/04/13/masks-summary/

6. Cross FB. Paradoxical perils of the precautionary principle. Wash Lee Law Rev. 1996;53(3):851928.

7. Sunstein CR. Beyond the precautionary principle. Univ Pa Law Rev. 2003;151(3):1003-58.

8. Harremoes P, Gee D, MacGarvin M, Stirling A, Keys J, Wynne B, et al., editors. The precautionary principle in the 20th Century: late lessons from early warnings. London: Taylor \& Francis; 2002.

9. Hedlund J. Risky business: safety regulations, risk compensation, and individual behavior. Inj Prev. 2000;6(2):82-9.

10. Nichol K, McGeer A, Bigelow P, O’Brien-Pallas L, Scott J, Holness DL. Behind the mask: determinants of nurse's adherence to facial protective equipment. Am $\mathrm{J}$ Infect Control. 2013;41(1):8-13.

11. World Health Organization. Advice on the use of masks in the context of COVID-19 [Internet]. Geneva: WHO; 2020. Available from: https://www.who.int/publications-detail/advice-on-the-useof-masks-in-the-community-during-home-care-and-in-healthcare-settings-in-the-context-of-thenovel-coronavirus-(2019-ncov)-outbreak

12. Maclntyre CR, Seale H, Dung TC, Hien NT, Nga PT, Chughtai AA, et al. A cluster randomised trial of cloth masks compared with medical masks in healthcare workers. BMJ Open. 2015;5(4):e006577.

13. Houston DJ, Richardson LE. Risk compensation or risk reduction? Seatbelts, state laws, and traffic fatalities. Soc Sci Q. 2007;88(4):913-36.

14. Esmaeilikia M, Radun I, Grzebieta R, Olivier J. Bicycle helmets and risky behaviour: a systematic review. Transp Res Part F Traffic Psychol Behav. 2019;60:299-310.

15. Kasting ML, Shapiro GK, Rosberger Z, Kahn JA, Zimet GD. Tempest in a teapot: a systematic review of HPV vaccination and risk compensation research. Hum Vaccines Immunother. 2016;12(6):1435-50.

16. Hagel B, Meeuwisse W. Risk compensation: a "side effect" of sport injury prevention? Clin J Sport Med. 2004;14(4):193-196.

17. Asmundson GJG, Taylor S. Coronaphobia: fear and the 2019-nCoV outbreak. J Anxiety Disord. 2020;70:102196.

18. Horton R. Offline: COVID-19 and the NHS_'a national scandal.' The Lancet. 2020;395:1022.

19. Maclean R, Marks S. 10 African countries have no ventilators. That's only part of the problem. New York Times, 18 April 2020.

20. Maxin D, Sega L, Eaton L. The cumulative effect of risk compensation on infection preventive measures. Theor Popul Biol. 2016;112:109-16.

21. Voermans WJM. Gold-plating and double banking: an overrated problem? In: Snijders HJ, Vogenauer S, editors. Content and meaning of national law in the context of transnational law. Munich: Sellier European Law Publishers; 2009. pp. 79-88.

22. Braithwaite J, Churruca K, Long JC, Ellis LA, Herkes J. When complexity science meets implementation science: a theoretical and empirical analysis of systems change. BMC Med. 2018;16:63.

23. Plsek PE, Greenhalgh T. The challenge of complexity in health care. BMJ. 2001;323(7313):6258.

24. Bonell C, Jamal F, Melendez-Torres GJ, Cummins S. 'Dark logic': theorising the harmful consequences of public health interventions. J Epidemiol Community Health. 2015;69(1):95-8.

25. Reed JE, Howe C, Doyle C, Bell D. Simple rules for evidence translation in complex systems: a qualitative study. BMC Med. 2018;16(1):92.

26. Oliver K, Kothari A, Mays N. The dark side of coproduction: do the costs outweigh the benefits for health research? Health Res Policy Syst. 2019;17(1):33.

27. Wynne B. Public uptake of science: a case for institutional reflexivity. Public Underst Sci. 1993;2(4):321-37. 